ISSN 2002-3898

(C) Ellen Saur, Oddbjørn Johansen and Nordic Theatre Studies

DOI: https://doi.org/ 10.7146/nts.v25i1.110897

Published with support from Nordic Board for Periodicals in the Humanities and Social Sciences (NOP-HS)

\title{
Being Actors with Learning Disabilities in a Democratic Perspective
}

\author{
Ellen Saur and Oddbjørn Johansen
}

\begin{abstract}
The Nordic welfare model is based upon the democratic value of the equal rights of all citizens to live a dignified life. In 1991, a decisive reform in Norway transferred the responsibility for people with learning disabilities from central state and county governments to the local municipality where they were born. The intention was to give them the same rights and obligations as other citizens, and the large segregated residential institutions, the asylums, were closed down. In this article we will share our experiences from working within Teater nonSTOP, a political theatre employing fifteen professional actors with learning disabilities.

The theatre is now owned by the local municipality, following a three-year trial period during which we worked as project leaders responsible for conducting research and documenting the activities at the theatre. In this article we draw on the theories of Pierre Bourdieu and Jacques Rancière in a discussion of the ways in which the struggle for equality affects the subjectification process of the actors at Teater nonSTOP. With reference to three different performances we ask the questions: in what way was equality an issue, and what were the artistic consequences of choosing equality as a dramaturgical point of departure?
\end{abstract}

\section{BIOGRAPHY}

Ellen Saur and Oddbjørn Johansen, former co-leaders of Teater nonstop (www.teaternonstop.no), have published articles about the theatre project in Uniped, Drama: Nordic Journal of Drama Pedagogy and RiDE: Research in Drama Education. Saur, PhD and MA in Drama and Theatre, is Associate Professor at the Department of Education, the Norwegian University of Science and Technology Trondheim (NTNU). Johansen is Associate Professor within the Social Education Program at the Department of Health, the University College of Nord-Trøndelag. 


\section{Being Actors with Learning Disabilities in a Democratic Perspective}

\section{ELLEN SAUR AND ODDBJØRN JOHANSEN}

A core value in a modern democratic society is having a voice that is heard and considered when decisions are made. An important political aim for people with disabilities has been to be included into society with equal rights, and in which they are accepted with their differences rather than being excluded and marginalized. In this article we will contribute to the discussion of how theatre can be an arena for the exploration of the democratic challenges faced by people with learning disabilities.

\section{METHODOLOGICAL APPROACHES}

Between 2009 and 2012, the authors of this article were project leaders of Teater nonSTOP ${ }^{1}$ and received financial support to conduct research and document the activities at a theatre where the goal is the development of artistic activities in collaboration with partners from the local community: the Health and Care Department and the Culture Department of the municipality. To deal with this complex challenge, which involves the artistic, organizational as well as political development of the theatre, we chose an approach based on action research. Action research is, according to Jean McNiff and Jack Whitehead, ${ }^{2}$ a form of enquiry that enables practitioners to come face to face with their own practical theories of practice, and where the aim is to improve their own practice. Within the frame of action research we conducted ethnographic research, using interviews, performance analyses and archival research, and we also organized and took part in some of the productions as actors, playwrights and directors. ${ }^{3}$ Since it was a challenge to benefit from this close involvement in the daily activities of the theatre while maintaining a critical stance toward our involvement, we also visited other theatres that employ actors with learning disabilities, including Allateatern in Sweden ${ }^{4}$ and Maatwerk in the Netherlands. ${ }^{5}$ We met, too, with Tony McCaffrey from the Different Light Theatre in New Zealand. ${ }^{6}$ What we apparently had in common was the feeling of being divided between a theatre discourse and a health-and-care discourse, and of challenging both aesthetics and politics. Artistic expressions made by people with learning disabilities are still today often understood within the frames of therapy and education, as a means to develop their dis-abilities, not looked upon as a genuine expression of $\operatorname{art}^{7}$. But according to Barnes and Mercer, the growing politicization of disabled people has prompted the search for an alternative disability culture. ${ }^{8}$

\section{TEATER NONSTOP - A POLITICAL THEATRE}

In 2008 we prepared the establishment of Teater nonSTOP, and in August 2009 fifteen actors with learning disabilities were employed by the Municipality of Namsos. The project was given a trial period of two and a half years, financed by Nord-Trøndelag County Municipality, the Municipality of Namsos and Nord-Trøndelag University College. The University College was in charge of the research aspects, and social education students used the theatre as an arena for their practical studies. In 2012 Teater nonSTOP became a part of the Culture Department in 
the Municipality of Namsos, and fifteen actors are still employed at the theatre today.

The actors have different levels of functionality and include people with Down syndrome, William's syndrome and other diagnoses. The level of disability is not a criterion for employment. Most of the actors live in group residences with care staff supporting their daily activities. They must apply for the job through regular job application channels in the municipality, which hosts the theatre. The main goals are to provide actors with disabilities a platform that allows them to communicate their experiences and view of the world using their own voices, and to give them an opportunity to develop their own mode of expression. This may be regarded as a form of applied theatre ${ }^{9}$ since drama and theatre are used to improve the lives of individuals and thereby create a better society. ${ }^{10}$

The stated primary aims of the theatre are the following: "Teater nonSTOP is to be a professional theatre for actors with learning disabilities. The theatre will promote the aims and interests of the actors, both politically and artistically. This implies developing methodical approaches that serve this group in a way that makes their qualifications appreciated and draws attention to their artistic interests. The theatre will be a means for the actors to communicate their own experiences and circumstances of life. The theatre will also contribute to making this group of people more visible in society." As appears from these goals, Teater nonSTOP is a theatre with political visions that involve issues of democracy and emancipation. Before looking into the productions of the theatre, we will take a closer look at these concepts.

\section{DEMOCRACY, EQUALITY AND EMANCIPATION}

According to the French philosopher Jacques Ranciére, democracy happens when the demos (the people) are heard and seen, ${ }^{11}$ and the possibility for even marginalized voices to break through. In ancient Greek democracy, the demos were defined as men with property, i.e. neither slaves nor women. Who is considered the demos has changed over the years. In 2013 Norway celebrated the centenary of women's suffrage, but in Switzerland the right to vote was given to women as late as in 1971. It is not a given that the demos includes all groups of citizens, not even today. Just think of children, people with disabilities, those with psychiatric diagnoses, refugees and old people suffering from dementia and Alzheimers. Which voices are being silenced even in the 'democratic' western world today? In the 201112 report Culture, Inclusion and Participation, ${ }^{12}$ the Storting (the Norwegian Parliament) asserted that it is the duty of the community to increase the participation in cultural activities of all people, regardless of race, social status, gender, and mental and physical ability. The same report referred to figures according to which people with disabilities are under-represented both among consumers of art as well as among performing artists. It is in this light that the space given to these particular actors by Teater nonSTOP may be understood as an act of democratization.

We will start our discussion of these challenges by comparing Jacques Rancière's views of equality, democracy and emancipation with sociologist Pierre Bourdieu's theory of the reproduction of cultural capital. According to Rancière, democracy is not defined by consensus, but by 'dissensus', which happens when marginalized voices are able to break through walls of prejudice and suppression; equality and emancipation are understood along the same lines. "Equality is a presupposition, an initial axiom - or it is nothing", says Rancière. ${ }^{13}$ In other words, equality is not the goal that one should try to reach, but the starting point. It is the opposite of the dominant hegemony, which manifests itself in the 'myth of pedagogy'. We are used to subordinating the pupils to the teachers, regarding the teachers as the ones with the superior knowledge, and the pupils as the ones waiting for their explication. In the process of explication, however, the teachers divide the children into the slow and the quick-witted, and the consequence is inequality. ${ }^{14}$ So in order to obtain emancipation in the education system, as well as elsewhere in society, one needs an awareness of oneself as the equal of any other and of others as the equals of oneself, which axiom needs constant verification. "What makes an act political is when it stages the contradiction between the logic of the police order and the logic of equality, that is, 
when it brings into a relationship two unconnected, heterogeneous and incommensurable worlds: the police order and equality. This is why dissensus lies at the heart of political acts". ${ }^{15}$

As pointed out, democracy has been viewed differently throughout history. Plato's view was that it was for the elite to take part in decision-making. Most people did not have the wisdom required to govern. Everyone had their place in the hierarchy. For Plato it was the elite that was considered the demos and who exercised democracy. Some might find that this is still the case, as it is difficult to cross the borders between social strata in many societies, and according to Rancière, the possibility of crossing these borders is the democratic challenge: "The democratic voice is the voice of those who reject the prevailing social distribution of roles, who refuse the way a society shares out power and authority, the voice of "floating subjects that deregulate all representations of places and portions"”. ${ }^{16}$ In many respects, power is still shared out from the hands of white men with property. According to Bourdieu, social inequality is not only reproduced by the mechanisms of economic power; cultural capital is another important factor that creates inequality. In order to gain acceptance within the circles of power, one must master the symbols and the language, and know what is considered good taste. Without commanding these codes, it may be difficult to get access to the power; the school system is designed for the middle class, the teachers reward the students that understand the codes of the middle class and are likely to punish the working-class children by giving them less attention, or only negative attention for inappropriate behaviour. In Pierre Carle's biographic film about Bourdieu, La sociologie est un sport de combat, ${ }^{17}$ the sociologist becomes upset at a public meeting in an area with many immigrants, when he finds the people hostile to intellectuals. Instead of mobilizing in order to create changes in their environment, they harbour an antagonistic attitude towards society outside their suburban area. Bourdieu encourages the participants to read his works, to search for tools they can use in their fight for dignity, justice and a more advantageous distribution of resources, rather than sinking further into depression and despair. Although Bourdieu's reaction is understandable, he might be said to be digging his own grave, since encouraging the immigrants to read his books written from his special point of view may be understood as an admission that the bourgeois class is the ultimate point of reference that one has to accept and adapt if you want to achieve social changes. Bourdieu's works have without doubt contributed greatly to understanding how social inequality is reproduced, and why it seems difficult for marginalized groups to get access to real power even though, in principle and according to the law, they have equal rights. ${ }^{18}$ In spite of his great influence, Bourdieu is also criticized for being elitist, a sociologist who uses the underprivileged as research objects, but does not identify with them. ${ }^{19}$ Even though one might agree with this criticism, Bourdieu clarifies the dilemma of achieving democracy with equal rights for all: it is essential that one is seen and heard, and the central issue is whether one masters the symbolic and cultural capital of the upper class and the middle class. Many people with learning disabilities will never be able to master spoken language at all and are unable to develop a strategy for overcoming these obstacles.

Jacques Rancière has criticized Bourdieu for regarding inequality as the starting point, and for seeing the goal as gaining power by taking possession of the symbolic and cultural capital of the ruling class. According to Rancière, the starting point must be that everyone is equal, and democracy and emancipation are about proving equality, not regarding equality as something we struggle for as the means to an end. He differs from Bourdieu in the distinction he makes between identification and subjectification, which seems relevant to the study of theatre with actors with learning disabilities. Subjectification is "the production through a series of actions of a body and a capacity for enunciation not previously identifiable within a given field of experience, whose identification is thus part of the reconfiguration of the field of experience", whereas identification "is about taking up an existing identity, that is, a way of being and speaking and of being identifiable and visible that is already possible within the existing order" ${ }^{20}$ Subjectification differs from identification because it adds something to an existing situation, and it "is highly 
political because as it intervenes in and reconfigures the existing order of things, the existing division or distribution of the senses". ${ }^{21}$ "Democracy thus establishes new, political identities," Rancière says, "identities that were not part of and did not exist in the existing order - and in precisely this sense it is a process of subjectification". ${ }^{22}$ Rancière is concerned with the connection between aesthetics and politics in his emphasis on the duty of democratic society to listen to the voices of marginalized groups. Aesthetics opens up for new approaches, new ways of seeing, hearing, sensing and perceiving, and politics becomes aesthetic when it contributes to new ways of approaching the world. As Peter Hallward says, "Rancière names the 'aesthetic revolution', to move from a rule-bound conception of art preoccupied with matching any given object with its appropriate form of representation (the basis for a secure distinction of art from non-art) to a regime of art which, in the absence of representational norms embraces the endless confusion of art and non-art". ${ }^{23}$ To Rancière, the potential of art resides in its ability to challenge our ideas and conceptions, which is a premise for democracy and equality. ${ }^{24}$

\section{DEMOCRATIC CHALLENGES FOR PEOPLE WITH LEARNING DISABILITIES}

From a social constructivist perspective, people with learning disabilities can be said to have been understood and categorized differently, depending on the historical, geographical or social context, ${ }^{25}$ and there is a long history of excluding and even killing children with disabilities. Many thousands were killed in Hitler's death camps. Euthanasia programs for racial hygiene were not only a Nazi phenomenon, however. Even pre-war Norway had programs to prevent people with learning disabilities from giving birth. The abandonment of children with learning disabilities also continued after the Second World War. In Norway, it was not unusual to find children stowed away from public view in barns and basements, living under terrible conditions, as late as in the 1960s. Today, controversy surrounds the ability of modern medical technology to reveal whether a foetus has e.g. Down's syndrome, enabling the mother to have an abortion because of the diagnosis, which critics have described as simply another form of euthanasia.

Furthermore, twenty-three American states carry out the death penalty even if the convicted have been diagnosed with learning disabilities. ${ }^{26}$ The Texas Tribune observed, when Marvin Wilson was executed in Texas in 2012: "Ten years ago, this court categorically barred states from executing people with mental retardation [...] Yet, tonight Texas will end the life of a man who was diagnosed with mental retardation by a court-appointed, board-certified specialist $[\ldots]$ the criteria Texas uses to determine mental disability in death penalty cases is a 'decayed remainder of an uninformed stereotype that has been widely discredited."' 27 To determine who is mentally retarded in these cases, says the critic, the state of Texas uses the fictional character Lennie Small from John Steinbeck's Of Mice and Men as the standard determining whether a man is eligible for execution in developing the three-part so-called Briseo factors that are used to determine mental disabilities. The Texas court invoked, in part, an evaluation of Lennie. Thomas Steinbeck, the son of John Steinbeck, said his father would be 'deeply angry and ashamed' to know that. Thomas Steinbeck joined anti-death penalty advocates in objecting to the lethal injection of Marvin Wilson, whose lawyers say he has an IQ of 61, so low that his execution would be unconstitutional. ${ }^{28}$ There are, then, still clearly many severe democratic challenges to people with learning disabilities, even if we leave aside the use of force in treatments and in everyday life, and the fact that the economic crises in Europe has struck this group hard, welfare states having come under pressure.

These democratic challenges are interconnected issues based on attempts of normalization. Normalization was a core value in the disability politics from the 1950s when the large asylums and the institutionalized lives people lived there were first questioned. The goal was to "generate an environment for people with learning disabilities that offered as 'normal' a life as possible". ${ }^{29}$ This normalization process was at its peak in Norway in the 1990s. In later years, one has begun to question if these normalization values have supressed the differences in individuality and even the needs of people with 
disabilities. These discussions are also brought into the open in the area of disability art. "Too many of us have forgotten the theoretical basis of the Disability Art movement," says Paul Anthony Darke, both an academic and an artist, "and the success of a few Disability Artists has been at the expense of the many. As a result, Disability Art and Disability Artists have become, largely through no fault of their own, a tool of the 'hidden forces' used against disabled people to legitimize their (our) continued mass exclusion from not just art culture but culture more widely". ${ }^{30}$

According to Rancière, however, aesthetics are able to turn things upside down, to create new approaches to politics, and for marginalized groups to take space. For people with learning disabilities it is important to give the public an understanding of their special ways of being in the world and of their humanity, in order to prevent the use of force, inhuman forms of housing and care etc., which was exactly the goal of our theatre project.

To describe the method developed at the theatre, we will look at three major productions.

\section{THE PRODUCTIONS - CONFIRMING THE ACTORS' IDENTITIES OR A POSSIBILITY FOR SUBJECTIFICATION? \\ Production 1}

The Story of Me was written and directed by Nina Wester, a well-known Norwegian director who is the current head of Hålogaland Teater, one of the major theatres in Norway. Wester's idea with the play, performed in Namsos Kulturhus on 6 June 2009, was to get hold of the dreams and wishes of the actors. She therefore interviewed them at their homes, asking them to bring artefacts that meant something special to them. Their dreams and wishes were then visualized on stage, in contrast to the narrow boundaries of the group housing, the encounters with the health-carer's and society's narrow view of normality. All the actors had their own marked square on the stage, representing their rooms in their group housing. In each marked space, they brought one or two things representing their interests or their dreams. It could be a picture of the TV hero MacGyver and a letter that the actor had written to him, telling him of her dreams. It could be popcorn and a CD player or it could be the trolley the actor used in his work as a handyman. Throughout the play, these marked squares also represented the rules they experienced being dependent on carers that have power to limit their boundaries in their everyday life. In the play they challenge these boundaries with their dreams acted out on stage. The director worked with the actors' own stories, describing the process as follows: "Working with these actors has been exciting and instructive. It demanded that I was very attentive to the needs and talents of each of them and that I saw possibilities instead of limitations. It has also been very important for me not to push the actors into traditional expectations of what theatre should be. We have searched for a more abstract vision, where pictures and fragmented scenes visualize the idea of the play". ${ }^{31}$ In other words, the director worked with the actors as a starting point, not working with a prewritten text. The actors took an active part in the development of the play. The stories they told were about joys as well as sorrows and regrets, about work, friendship and love, and about being governed by others. In the beginning, the director was reluctant about taking the job, fearing that the actors would let themselves be manipulated (disciplined) because of her power position and their desire to please her, and that they would not resist if they disagreed. This opened up a discussion about which decisions were related to the directing of theatre and which were related to the disciplining of the actors due to their disabilities, which were impossible to separate, of course. Distinguishing between them was an ethical challenge that required sensitivity to their special ways of being in the world: it might not be ethically defensible to silence their voices due to fear of stepping into the unknown, and it was indeed our experience that the actors offered resistance in their own ways, though not necessarily vocally. Sometimes they simply refused to do what they were told if they disagreed with the decisions.

After the performance, we interviewed leaders of the organizations involved in the project, partly in order to see if they could describe if and how experiencing the actors in their work at the theatre had made a potential difference for their institu- 
tion. These interviews were part of the action research design, where participation and community change on a wider scale were focused on. If these actors were going to continue to have a place in the community as an independent theatre, it was important to involve both the health and the culture departments. The Minister of Health said he could see why the management of the theatre emphasized quality and professional artistic expression. "Experiencing these actors on stage challenges the view of how we think of people with disabilities. In this theatre, these actors can show that they have qualities that are not very visible in the healthcare context. Even though all the employed actors are people with learning disabilities, we consider them individuals because the artistic qualities of each and every one of them find expression." 32 According to the Prorector of the University College, it had been liberating for the healthcare students to work with art, just as it had been for the actors, and through the medium of art, the concept of health was being re-negotiated. ${ }^{33}$ According to the Minister of Culture, "Teater nonSTOP makes a difference in Namsos. It's a flagship in our small community. The audience comes to watch the performances not because they feel pity for actors with intellectual disabilities, but because it's beautiful". ${ }^{34}$ These quotations might seem like happy party speeches, and it is indeed not easy to say in what way the various interviewees can commit to these views in their daily working practices. It is, however, important that those who are in charge of politics in the community are invited to take part in the theatre and are held responsible for this group of citizens, too. They should not just see them as having the fixed identity of "learning disabled" with the need for help, but also as someone having the power to create their own subjectivity.

So did working with The Story of $M e$ give the actors the chance to negotiate a new kind of subjectivity? This is clearly a difficult question to answer as the actors themselves are not verbally strong, but also because they do not seem to think in these terms. What we observed during their work process, however, was that the potential for subjectification lay in the aesthetic choices made by the director. Nina Wester gave them space to make their own interpretation of their everyday lives, but trans- formed it into theatrical language. They were also given the possibility to explore what subjectivity they wanted to express, even though it is difficult to know whether their participation and subjectification were based on their authentic and intellectual considerations. This we will never fully know, but that should not keep us from trying. One of the actors said of the relationship between the artistic choices and what she tried to communicate to the audience: "The popcorn and the ice cream - that was something we said and did, but what we really wanted to tell was that we are friends". ${ }^{35}$ She referred to her relationship to one of the others, who lives in the same group housing, which to them was an important part of the play. One of the issues in the play was the danger posed to their friendship by the regulations of the carers discussing the rules in the group housing.

\section{Production 2}

A Cup of Coffee, Perhaps? involved only one of the actors with learning disabilities, in addition to the authors of the article. It was premiered on 15 April 2010 and was performed thirty-five times. The play dealt with the sixty-five-year-old actress's experience of having been sent to a school for disabled children far away from home when she was twelve years old, and it questioned concepts of normalization and socially valued roles. Developing the play demanded research into the school, interviews with its former employees and the actress's sister, studying archival material together with the actress, and hearing her tell stories when she began to remember. Notably, she had not wanted to tell about this harsh epoch in her life before, not even to her family. In the theatre, though, she found a medium that gave her sufficient space and distance, as well as a safe environment that permitted her to re-experience it. One of her central motives to tell the story on stage was that, "it's important to tell others what it was like for me being a child. They shouldn't do things like that to a child" ${ }^{36}$ Borrowing Rancière's terms, hers might be described as a subjectification process rather than an identification process, because she was not being fitted into a fixed identity, but was recreating herself as a new subject, in a democratic sense. 
The actress had great difficulty learning lines of text because she got distressed and was afraid of making mistakes, but this was solved with the use of a photo album (and slides projected onto the wall on the stage). Chatting about the pictures helped her remember the topics she wanted to talk about. Importance was also given to the content rather than to saying things right, or using a lot of energy remembering. If she had been forced to learn her lines, her stage appearance would have been vulnerable and disabled, but by using her own way of expression, she appeared strong and self-confident. When this play toured high schools, the students have had the opportunity to discuss the play with the actress herself, and many have said that seeing it made them realize why an inclusive school is important, though such a school does not even exist, today. "How inclusive is the school," as one student observed, "when we, the other students, never meet or do something together with the students with learning disabilities, because they have their classrooms far away from the rest of us?" 37

\section{Production 3}

I-You, Us-Them, Inside-Outside was a dance performance premiered on 18 September 2011. The title and concept of the production drew on common words that reflect the distance created by society between people with learning disabilities and so-called normal people. ${ }^{38}$ The main focus was relationships. How do we relate to each other, including strangers we meet? How do we relate to space? Dancing with others includes 'listening' with the body, figuring out what choices the others make whilst simultaneously working with one's own body. It involves a physical dialogue between two or more people.

Our culture's body ideals and gender roles affect the way we dance and the way we understand dance. In our production, the starting point of the choreographers ${ }^{39}$ was non-narrative dance, as well as the idea that everybody can dance, and that all movements can become dance. Their work was anchored in the postmodern rejection of universal concepts of culture, according to which there are definitive ways of framing reality, postmodernists emphasizing that there are multiple ways of perceiving the world, experiencing and seeing the world. ${ }^{40}$

The choreographers explained to the group of actors how it is possible to communicate through dance; how dance can express words, emotions and different moods. The choreographer asked them to move around in the room, using the space. She gave instructions to movements such as 'high-low', 'quick-slow', 'inside-outside', inspired by Rudolf von Laban's theory on effort, shape and space, ${ }^{41}$ which exercises later became important in the performance. The actors were asked to think of antonyms, of words with opposite meanings. The choreographer suggested different ways of expressing these antonyms with different body shapes and movements and taught the actors to use dance techniques to express the differences in motions; something they had never been able to do before. Experienced jazz musicians were chosen as co-performers due to their skills in improvisation, ${ }^{42}$ which involved an awareness of the impulses of the actors who developed the material themselves, though within the framework of the dance exercises introduced by the choreographer. The use of dance and improvised live music on a high artistic level as a creative language for actors with learning disabilities seemed to challenge the spectators' prejudices concerning dance as well as learning disability. We saw how many audience members who appeared reluctant and biased before the performance - they still clung to their traditional concepts of dance and disability when reading about the production - admitted that they could not have imagined how it changed their perception before they actually experienced it.

We observed how the actors' everyday body language was challenged when they were obliged to work with their bodies in relation to music within a non-narrative framework. Of course, this goes for all actors and dancers, but people with learning disabilities often suffer from reduced body control and are therefore likely to develop stereotyped motoric patterns. By exploring new ways of bodily expression through artistic work, they were enabled to expand the expressive boundaries of their bodies, thereby discovering new possibilities for their subjectivity. 


\section{EQUALITY AS A STARTING POINT - NAÏVE OR INEVITABLE?}

What does it mean to make equality the starting point for disability theatre rather than produce theatre in order to have equality as the goal? By making the unexpected visible, one can create turmoil. When one is visible and claims space on a stage, it is not so easy to be oppressed without the oppression itself becoming visible, and the theatre offers an arena for subjectification where the actors can explore new identities. Here, actors with disabilities can verify equality, to use Rancière's term, by insisting on being considered professional artists, even if theatrical convention is thereby challenged. They represent a democratic voice in their defiance of established views on what constitutes high artistic quality when they are enabled to create and perform theatre based on their individual experiences without these being filtered through the able bodies, voices and interpretations of others. To achieve this it was necessary to choose artistic methods and texts that have equality as a starting point. Here, it was important to consider that many people with disabilities are unable to speak, and if equality is defined by the command of spoken language, these actors will never live up to the standards. Trying to do so, in fact, might make them feel even more disabled because they cannot attain the required skills. But by using their own voices and bodily expressions, they can take action on their own terms, making equality the starting point and contribute to democracy through "rupture of the existing order" (Rancière).

According to Paul Anthony Darke, “[d]isability art is a challenge to, an undermining of (as a minimum), traditional aesthetic and social values [...]. Disability art is a threat to the core aesthetics values of contemporary cultures". ${ }^{43}$ Darke's claim challenges us to dare let the actors develop their own aesthetics and withstand the temptation to manipulate performers who lack an oral language into conforming to 'the core values' of contemporary culture. This leaves artists with disabilities out if they do not act within the frames of normality. As Darke states, we reject their disability and leave it outside the aesthetic production. Taking Darke's statement into consideration together with Rancière's view, disability art is a democratic voice because of the ruptures and discussions that it creates. Just the appearance of actors with learning disabilities might, for some, be regarded as a dissonance or an anachronism, and it makes a difference when an actor with Down's syndrome dances with a skeleton on stage and for some symbolises the ongoing debate on aborting foetuses with an extra chromosome. When directing actors with learning disabilities, it turned out to be very important that we avoided 'othering' them by subjecting them to our normalizing gaze and our conceptions of inclusion and exclusion. ${ }^{44}$ Many actors with learning disabilities have difficulties grasping the effects and consequences of their appearance on stage, which requires constant ethical considerations on the part of the directors and producers about whose voice is being transmitted. We continually needed to ask ourselves whether the decisions were made for the benefit of those in charge, or for the actors, and whether we were tempted to conform to traditional aesthetic and social values.

Most of the actors with learning disabilities with whom we worked were neither aware of nor interested in these ethical discussions, but were simply happy to do the artistic work on stage that they loved, without caring much about the consequences outside the theatre except from the immediate reactions of the audience. Some of the actors said working in the theatre was "fun" and "makes me proud", that it was "fun being together with the students and teaching them what I can", or simply that "I like being at the theatre". ${ }^{45}$

From the theoretical approaches of Bourdieu and Rancière, we have learnt that Bourdieu can be useful in uncovering the patterns of power and how culture seems to be encapsulated in our habitus. In order to get past the hierarchy of power relations, the hope for actors with learning disabilities is not to get access to the symbols and language of the dominant view reproducing normalization through theatre, but instead - in Rancière's terms - create rupture and challenge the order by letting the voices of actors with disabilities break through and give the spectators the possibility to take part in their ways of interpreting their own experiences presented on a democratic stage, thus verifying inclusion based on difference not normalization standards as a starting point. 


\section{NOTES AND REFERENCES}

1 www.teaternonstop.no (retrieved 2 October 2013).

2 Jean McNiff and Jack Whitehead, All You Need to Know about Action Research, Sage, London 2006.

3 Norman K. Denzin, Interpretive Ethnography, Sage, Thousand Oaks, Calif. 1997.

4 Cf. Lennart Sauer, Teater och utvecklingstörning. En studie av Ållateatern, dissertation, UmeåUniversitet 2004.

5 http://www.theatermaatwerk.nl/en (retrieved 2 October 2013).

6 http://www.differentlight.co.nz/ (retrieved 2 October 2013).

7 Ellen Saur, Kulturarena med mulighet for dialog?: Grotta - en fritidsklubb for mennesker med utviklingshemming, $\mathrm{PhD}$ thesis, Norges teknisk-naturvitenskapelige universitet, Trondheim, 2008.

8 Colin Barnes and Geof Mercer, Exploring disability, second edition, Polite, Cambridge 2010 p. 185.

9 Helen Nicholson, Applied Drama: The Gift of Theatre VIII, Palgrave Macmillan, Basingstoke 2005, p. 196.

10 Oddbjørn Johansen and Ellen Saur, "Teater nonSTOP. Et profesjonelt teater med kunstnerisk og politisk verdi?” in Nordisk Tidsskift for Drama, 2 October 2010, pp. 33-7.

11 Jacques Rancière, On the Shores of Politics, Verso, London 1995.

12 Kulturdepartementet (2011-12), "Kultur, inkludering og deltaking” in Kulturdepartementet, St. melding no. 10, Oslo 2011-12, p. 127.

13 Jacques Rancière, The Philosopher and His Poor, Duke University Press, Durham and London 2003, p. 223.

14 Peter Hallward, "Jacques Rancière: Politics and Aesthetics: An Interview: Introduction Peter Hallward" in Angelaki Journal of the Theoretical Humanities, vol. 8, 2 August 2003.

15 Charles Bingham and Gert Biesta, Jacques Rancière: Education, Truth, Emancipation: With A New Essay by Jacques Rancière, Continuum, London 2010.

16 Hallward, op. cit., p.192.

17 Pierre Carle, La sociologie est un sport de combat, C-P Productions et VF Films 2001.

18 Pierre Bourdieu and Jean-Claude Passeron, Reproduction in Education, Society and Culture, Sage Studies in Social and Educational Change 1977.

19 Caroline Pelletier, "Emancipation, Equality and Education: Rancière's Critique of Bourdieu and the Question of Performativity" in Discourse: Studies in the Cultural
Politics of Education, 30 (2), October 2008, pp. 137-50. Discourse is available online at: http://www.informaworld.com/10.1080/01596300902809054 (retrieved 2 October 2013).

20 Bingham and Biesta, op. cit., p. 33.

21 Ibid. p. 33.

22 Ibid. p. 35

23 Hallward, op. cit., p. 193.

24 Anne Beate Maurset, "Etterord. Jacques Rancière - en talsmann for likhet” in Jacques Rancière, Sanselighetens politikk, Cappelen, Oslo 2013.

25 Mark Rapley, The Social Construction of Intellectual Disability, Cambridge University Press, Cambridge 2004, p. 246.

26 Store Norske leksikon, keyword: dødsstraff, http://snl. no/d\%C3\%B8dsstraff (retrieved 2 October 2013).

27 Brandi Grissom, “Steinbeck: Lennie Shouldn't Bolster Execution" in The Texas Tribune, updated 8 August 2012: http://www.texastribune.org/texas-dept-criminal-justice/death-penalty/advocates-texas-will-execute-mentally-retarded-inm/ (retrieved 2 October 2013).

28 Ibid.

29 Colin Barnes and Geof Mercer, op. cit., p. 74.

30 Paul Anthony Darke, "Now I Know Why Disability Art Is Drowning in the River Lethe (With Thanks to Pierre Bourdieu)" in Sheila Riddel and Nick Watson, eds., Disability, Culture and Identity, Pearson Education, Eastbourne 2003, pp. 131-42.

31 Quotation from the director Nina Wester and her introduction to the play Eventyret om meg (The Story of me) in the program presenting the performance. Our translation.

32 Interview with The Minister of Health in the municipality. Also a board member of the theatre. Interview conducted by us in May 2011.

33 Interview with the Prorector of The University College of Nord-Trøndelag. Also a board member of the theatre. Interview conducted by us in May 2011.

34 Interview with the Minister of Culture in the municipality. Also a board member of the theatre. Interview conducted by us in May 2011.

35 Interviews of the actors conducted by us in November 2013.

36 The actor interviewed and quoted in the Newspaper Trønderavisa 13 March 2010 before the premiere of the play Litt kaffe, kanskje (A Cup of Coffee, Perhaps?).

37 Quotation from an upper secondary student after seeing 
the play Litt kaffe, kanskje, 26 October 2011 at Steinkjer Upper Secondary School.

38 Johansen and Saur, op. cit.

39 The choreographer was Kirsten Roll-Steen.

40 Adam Benjamin, Making an Entrance: Theory and Practice for Disabled and Non-Disabled Dancers, Routledge, London 2002, p. 255.

41 Ibid.

42 Musicians were John Pål Inderberg and Henning Sommerro.

43 Darke, op. cit.

44 Cf. Petra Kuppers, Disability and Contemorary Performance: Bodies on Edge, Routledge, New York 2003.

45 Interviews of the actors conducted by us in November 2013 